\title{
Mathematics Anxiety Factors and Their Influence on Performance in Mathematics in Selected International Schools in Bangkok
}

\author{
Shamim Nisar Shaikh \\ St. Theresa International College, Thailand \\ Simranbkk@yahoo.com
}

\begin{abstract}
The objectives of this study were: 1) To determine the level of Performance in Mathematics of Grade 4 students in selected international schools in Bangkok in terms of Knowledge skills, Comprehension skills, Application skills, Analysis skills, Synthesis Skills, and Evaluation skills; 2) To determine the level of Mathematics Anxiety of Grade 4 students in terms of Cognitive factors, Psychological factors, Physical factors, and Environmental factors; 3) To investigate the influence of Math Anxiety factors on Performance in Mathematics. The study utilized the descriptive method. The instrument employed for collecting the data was a Math Anxiety Opinionnaire (MARS) developed by Richardson and Suinn (1972), and its many shorter derivations (Alexander \& Martray, 1989; Plake \& Parker, 1982; Rounds \&Hendel, 1980; Suinn \& Winston, 2003). The Math Test was based on the curriculum of Grade 4. The statistics used for the treatment of the data were mean, standard deviation(s.d.), standard error mean (s.e.mean), coefficient of variation(C.V.),rank and ANOVA. The results showed that the highest level of Performance in Mathematics is in the Comprehension skills and the lowest is Knowledge skills. Environmental factors produce the highest level of anxiety among the students. Physical factors had the highest influence on Performance in Mathematics.
\end{abstract}

Keywords: Mathematics anxiety, Mathematics performance, International Schools, Anxiety factors, Anxiety level

\section{Introduction}

Background of the study: There is a common perception that mathematics is a very difficult subject. As much as possible students tend to avoid taking math courses. Avoiding math courses severely restricts the fields a student can study and the jobs one can find Nowadays however, many have realized the importance of Mathematics, not only from the point of view of getting an academic qualification at school or college, but is also a subject that prepares one for the future as well, irrespective of which walk of life one chooses to be a part of. (www.mathematics blurtit.com) Like any other subjects, there are Math disabilities, which keep children from performing to their full potential in school and beyond. At no time in history has this notion been truer. As the world's reliance on technology has grown, so too has the demand for people who can think in the abstract terms of math and science. The disparity between those who learn math with relative ease and those who struggle with math disabilities is widening at an alarming rate. Research indicates that there are a number of reasons these students experience difficulty learning mathematics (Mercer, Jordan, \& Miller, 1996; Mercer, Lane, Jordan, Allsop, \& Eisele, 1996; Mercer \& Mercer, 1998; Miller \& Mercer, 1997). The research-based math disability characteristics include: learned helplessness, passive learners, memory problems, attention problems, cognitive thinking deficits, low level of academic achievement, and Mathematics Anxiety. Math disabilities can arise at nearly any stage of a child's scholastic development. While very little is known about the neurobiological or environmental causes of these problems. Mathematics may be the most Anxiety-provoking subject taught in a classroom. For many adults, especially those who avoided math in school, facing a column of numbers makes their palms sweat and their heart race. In fact, many of today's Math-Anxious parents probably learned their fear from their own parents or elementary school teachers who also felt incompetent when it came to working with numbers. It is a cycle that, unfortunately, can be passed on to today's children as well. While there is no evidence to show that Mathematics Anxiety is genetic, it clearly seems to be contagious. The issue of Mathematics Anxiety is significant for both children and parents.

Statement of the problem: Nurturing ability of mathematics problem solving is an important task. The Institute for the Promotion of Teaching Science and Technology (IPST 1997) in Thailand has stated that studying mathematics plays a very important role in developing human thinking to be more creative, reasonable, and able to analyze problems and to forecast the future. On the other hand, Thai education 
has been emphasizing the textbooks and its memorization rather than nurturing critical analysis. This trend is thought to obstruct students to develop mathematical skills. WHO (1990-2000) also reported that Thai education process in school has centered on memorizing textbook materials rather than developing self learning abilities. Examination rely mostly on memorization of knowledge, and that results in drawbacks like students' low capability in thinking, analyzing, synthesizing, innovating, and problem solving. In Thailand, there have been some researches in mathematical problem solving. One was done by using "Newman technology "(Natcha and Satoshi, 2006). The other one done in Mahasarakham (Sakorn, Tayruakham \& Nuangchalerm, 2009) was mainly focused on factors like motivation and self-efficacy, attitude towards mathematics, self-esteem and teachers' teaching behavior. There are no significant studies however which were mainly focused on Mathematics Anxiety, despite the fact that Mathematics Anxiety has been identified in the literature as a problem on the mathematical achievement of students. So it is necessary to find out the factors which affect the Mathematics Anxiety of the students.

\section{Research Questions:}

A) What is the level of Performance in Mathematics of Grade 4 students in selected international schools in Bangkok in terms of

- Knowledge skills

- Comprehension skills

- Application skills

- Analysis skills

- Synthesis skills

- Evaluation skills

B) What is the level of Mathematics Anxiety of Grade 4 students in selected international Schools in Bangkok in terms of the following

- Cognitive factors

- Psychological factors

- Physical factors

- Environmental factors

C) What Math Anxiety factors influence Performance in Mathematics of Grade 4 students in selected international school in Bangkok?

Figure 1: Conceptual Framework of the Study

\begin{tabular}{|l|l|l|}
\hline Mathematics Anxiety & \multicolumn{1}{|l|}{$\begin{array}{l}\text { Mathematics Performance } \\
\text { a) Cognitive factors }\end{array}$} & $\begin{array}{l}\text { a)Knowledge skills } \\
\text { b) Comprehension skills } \\
\text { b) Psychological factors }\end{array}$ \\
\cline { 2 - 3 } c) Physical factors & c) Application skills \\
d) Environmental factors & d)Analysis skills \\
& e)Synthesis skills \\
\hline
\end{tabular}

As shown in Figure 1, Mathematics Anxiety consists of cognitive factors, psychological Factors, physical factors and environmental factors. Mathematics Performance is in terms of Knowledge skills, comprehension skills, application skills, analysis skills, synthesis skills and evaluation skills.

\section{Literature Review}

There are many studies which have proved that different Mathematics Anxiety factors influence the Performance in Mathematics of the students. But these studies mainly have been done in secondary schools and colleges. These studies have proved the negative effects of Mathematics Anxiety on students' achievement which have interested researchers for several years. Richardson and Woolfolk (1980) discussed how certain features of Math, such as its precision, logic, and emphasis on problem solving, make it particularly anxiety provoking for some individuals. Studies have documented the negative effects of Mathematics Anxiety on math performance and achievement (Richardson \&Suinn, 1972; Suinn, 
Edie, Nicoletti, \& Spinelli, 1972). Several researchers also have proposed that Mathematics Anxiety contributes to observed sex differences in mathematics achievement and course enrollment patterns ( Fennema,1977; Fox, 1977; Tobias \& Weissbrod, 1980) .Mathematics Anxiety can interrupt and even make everyday activities of an individual difficult, such as balancing a checkbook, developing a household budget or simply calculating a restaurant bill. In academic settings, Mathematics Anxiety affects an individual in school-related activities like classroom and standardized test taking, resulting in what Ashcraft and Faust (1994) called 'global avoidance'. In other words, math anxious individuals may avoid any mathematics courses or subjects involving mathematics. This may mean that math anxious individuals do not gain competence or mastery of mathematical operations and this may directly influence their performance in Mathematics (Hembree, 1990). For instance, there are students who study regularly, work hard in the classroom and finish their homework on time but are unable to present what they know because of their Mathematics anxiety. Some researchers believe that intrusive thoughts and worries about completing mathematical problems may interfere with working memory (Ashcraft \& Kirk, 2001) and so they lack the ability to excel or perform well. Montagano (2010) proved in her study "Dimensions of Math Anxiety in 9-11 Year Olds" that Mathematics anxiety first surface in Grade 4 indicating a need for a study that looks at mathematics anxiety in 9- to 11-year-old children. Recent studies in Europe showed that roots of the gap in mathematics achievement begin well before the first NAEP assessment in $4^{\text {th }}$ Grade (Lewis, 2001; Waanders, Mendez, \& Downer, 2007). "The Neurodevelopment Basis of Math Anxiety “ by Christina B. Young, Sarah S. Wu, and VinodMenon have proved that in a functional MRI study on 7- to 9-year-old children, math anxiety was associated with hyperactivity in the right region of the brain that is important for processing negative emotions. In addition, they have found that math anxiety was associated with reduced activity in posterior parietal and dorsolateral prefrontal cortex regions involved in mathematical reasoning. Research indicates that mathematics anxiety develops in a child mainly at the elementary school level, at the time that there occurs a shift from concrete to more abstract thinking ( Jackson \& Leffingwell, 1999).Although the relationship between Mathematics Anxiety and Performance in Mathematics may be indirect and is necessarily ambiguous with respect to the direction of causality, it is often assumed that high levels of anxiety impair performance. So it is very necessary to root out this anxiety factors of Math at this age level so students can enjoy Math.

\section{Methodology}

Research Design: This study used the descriptive method. Target population of this study was a group of grade 4 students in selected international schools in Bangkok. To identify the number of respondents of the study, purposive sampling was used. The details of the sample are shown in Table 1.

Table 1: Distribution of Respondents by School.

\begin{tabular}{lcc}
\hline \multicolumn{1}{c}{ School } & $\mathbf{N}$ & $\mathbf{\%}$ \\
\hline Modern International School & 26 & 21.00 \\
Trinity International school & 25 & 19.00 \\
Ekamai International School & 35 & 28.00 \\
International Pioneers School & 20 & 16.00 \\
Panasia International School & 15 & 12.00 \\
Glory International School & 6 & 4.00 \\
Total & 127 & 100.00 \\
\hline
\end{tabular}

As seen in Table 1, the highest percentage of respondents (35\%) came from Ekamai International School followed by Modern International School (26\%), Trinity International School (25\%), International Pioneers School (20\%), Panasia International School (15\%) and Glory International School (6\%).

Research Instruments: The research study was conducted through the use of a Mathematics Anxiety Scale and a Mathematics Achievement test. The Mathematics Anxiety scale was adapted from the original Mathematics Anxiety Rating Scale (MARS) developed by Richardson and Suinn (1972), and its many 
shorter derivations (Alexander \& Martray, 1989; Plake \& Parker, 1982; Rounds \& Hendel, 1980; Suinn \& Winston, 2003), and the Mathematics Anxiety Scale (MAS) from the Fennema and Sherman Mathematics Attitude Scales (Fennema \& Sherman, 1976). The scale had four factors namely cognitive factor, psychological factor, physical factor, and environmental factor. Each factor has 5 items. There are a total of 20 items in this scale. The Likert scale was used for interpreting the responses.

Math Achievement Test: Mathematics test is based on the prescribed syllabus for Grade 4 by the Ministry of Education of Thailand .It consists of 6 skills based on Bloom's taxonomy namely Knowledge, Comprehension, Application, Analysis, Synthesis and Evaluation. Each skill4 has 5 questions. Total marks for all 6 skills are 30 measuring the Performance in Mathematics of the students.

Validity and Reliability Test: As regards to the validity of the items in the Opinionnaire on Mathematics Anxiety Scale and Mathematics Achievement test, the researcher distributed these to 30 respondents who did not take part in the actual survey. The responses of these initial respondents were analyzed .Ambiguous items were changed, rephrased or simplified based on the recommendations of the expert validators. The Cronbach Alpha test was used to obtain the reliability coefficient of the Opinionnaire which is 0.854 or very high. The Cronbach Alpha test was used to obtain the reliability coefficient of the Math Test which is 0.744 or very high.

Data Collections Procedure: After, the researcher had conducted a pre-test of the Opinionnaire to establish its validity and reliability. Approval was obtained from the Faculty to administer the Opinionnaires to the Grade 4 students of the 6 international schools. Students were required to complete the Opinionnaires and Math test in 60 minutes. The data were organized and tabulated in preparation for analysis and interpretation. The following is the scale used for Mathematics Anxiety and Performance in Mathematics with the corresponding equivalent.

\begin{tabular}{lll} 
Mathematics Anxiety Scale & & \\
\hline DESCRIPTION & Range & Descriptive Equivalent \\
\hline I strongly agree that I have Mathematics Anxiety. & 16 or above & Very High \\
I agree that I have Mathematics Anxiety. & $12.00-15.99$ & High \\
I have no opinion that I have Mathematics Anxiety. & $8.00-11.99$ & Moderate \\
I disagree that I have Mathematics Anxiety. & $4.00-7.99$ & Low \\
I strongly disagree that I have Mathematics Anxiety. & 3.99 or below & Very Low \\
\hline
\end{tabular}

Mathematics Achievement Scale

\begin{tabular}{lll}
\hline \multicolumn{1}{c}{ Description } & Range & Descriptive Equivalent \\
\hline $\begin{array}{l}\text { The Performance in Mathematics is far above the } \\
\text { Expected level. }\end{array}$ & 24.00 or above & Very High \\
$\begin{array}{l}\text { The Performance in Mathematics is above the } \\
\text { Expected level. }\end{array}$ & $18.00-23.99$ & High \\
$\begin{array}{l}\text { The Performance in Mathematics is just within the } \\
\text { expected level. }\end{array}$ & Moderate \\
$\begin{array}{l}\text { The Performance in Mathematics is below the } \\
\text { expected level. }\end{array}$ & Low -11.99 & \\
$\begin{array}{l}\text { The Performance in Mathematics is far below the } \\
\text { expected level. }\end{array}$ & 5.99 or below & Very Low \\
\hline
\end{tabular}

\section{Data Analysis}

The data collected were coded and analyzed using the Statistical Package for Social Science (SPSS) Version 16.0 . 
Table 2: The level of Performance in Mathematics of Grade 4 students

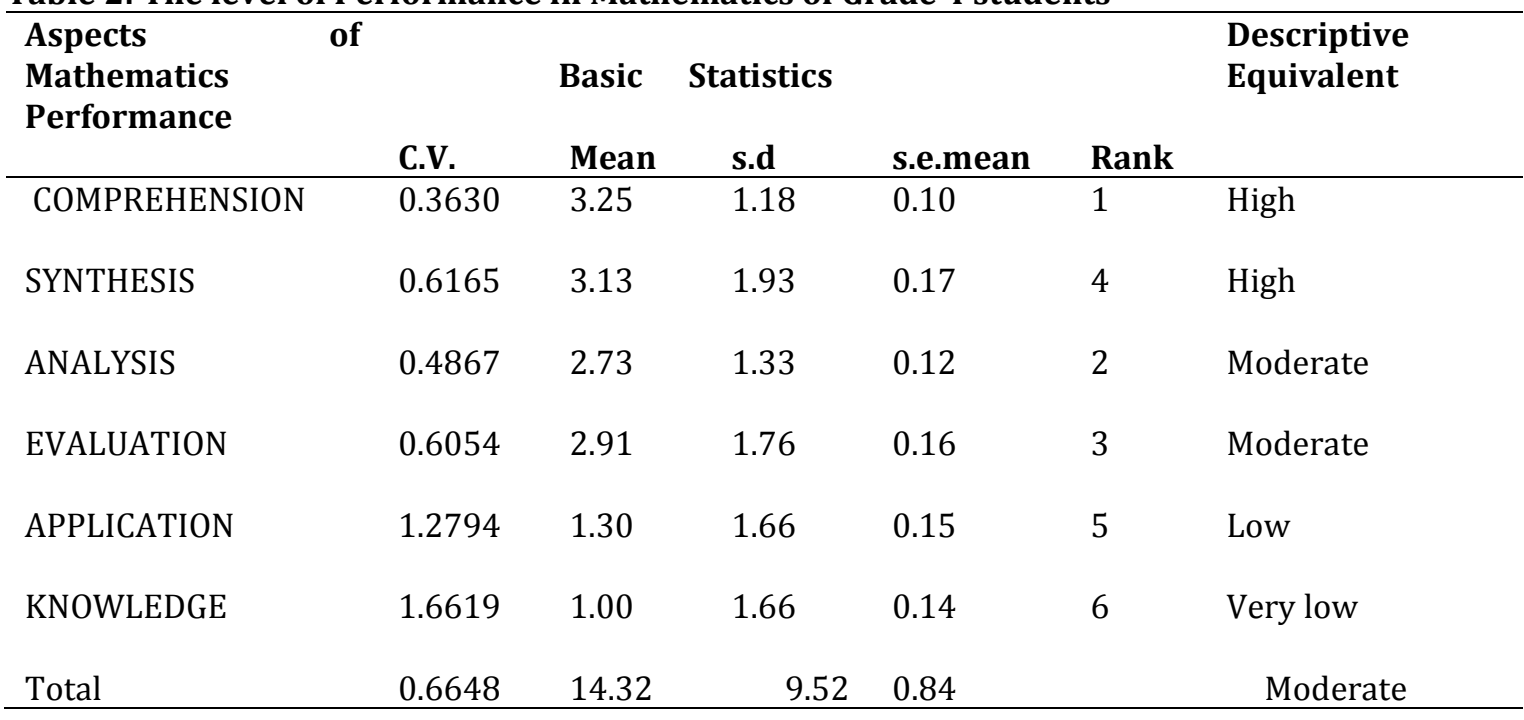

As shown in Table 2 the level of Performance in Mathematics of Grade 4 students was in Moderate level with the mean of 14.32and standard deviation 9.52.The value of mean of all the aspects of Performance in Mathematics varies from "Very low" to "High" By the values of C.V.(varies from 0.3630 to 1.6619),it shows that the variation of all the aspects of Performance in Mathematics of Grade 4 students were inconsistent or diverse and could be classified into 4 types (pattern of variations).The first one was Comprehension skills (C.V.=.3630), the second was Analysis skills (C.V.=0.4867), the third one was consist of Evaluation skills and Synthesis skills (C.V. $=0.6054$ and C.V.=0.6165), the last are consisted of Application skills and Knowledge Skills (C.V.=1.2794 and 1.6619) In terms of the ranks, of the Performance in Mathematics, it was found that Comprehension skills was the most important skills, while Application skills and Knowledge skills were the least important skills.

Table 3: The level of Mathematics Anxiety

\begin{tabular}{lllllll}
\hline $\begin{array}{l}\text { Aspects of } \\
\text { Factors }\end{array}$ & Rank & Mean & $\begin{array}{c}\text { Basic } \\
\text { s.d }\end{array}$ & $\begin{array}{c}\text { Statistics } \\
\text { s.e.mean }\end{array}$ & C.V. & $\begin{array}{l}\text { Descriptive } \\
\text { Equivalent }\end{array}$ \\
\hline $\begin{array}{l}\text { Environmental } \\
\text { Factors }\end{array}$ & 1 & 15.57 & 3.78 & 0.34 & 0.2425 & High \\
$\begin{array}{l}\text { Cognitive } \\
\text { Factors }\end{array}$ & 2 & 12.49 & 4.73 & 0.42 & 0.3790 & High \\
$\begin{array}{l}\text { Psychological } \\
\text { Factors }\end{array}$ & 3 & 12.56 & 5.01 & 0.44 & 0.3987 & High \\
$\begin{array}{l}\text { Physical } \\
\text { Factors }\end{array}$ & 4 & 10.42 & 4.32 & 0.38 & 0.4149 & Moderate \\
Total & & & & & & \\
\hline
\end{tabular}

As shown Table 3 the level of Mathematics Anxiety in Grade 4 students was in Moderate level with the mean of 51.04 and standard deviation 17.84.The values of the mean of all the factors of Mathematics Anxiety vary from "Moderate" to "High". By the values of C.V. (varies from 0.2425 to 0.4149 ), it could be seen that the variation of all the factors of Mathematics Anxiety of Grade 4 students were inconsistent or diverse and could be classified in to 3 types (pattern of variations), first pattern is of Environmental factor with coefficient variation 0.2425, then Cognitive factor and Psychological factor are consistent with coefficient variation 0.3790 and 0.3987 . The third pattern is of Physical with coefficient variation 0.4149. In terms of the ranks of the factors of Mathematics Anxiety, it was found that "Environmental" factor was the most important aspect, while "Physical" factor was the least important factor of Mathematics Anxiety. 
Table 4: Influence of Math Anxiety Factors on Performance in Mathematics: The results of multiple regression analysis of method enter and method stepwise for investigating the influence of Mathematics Anxiety factors on Performance in Mathematics are shown in Table 4

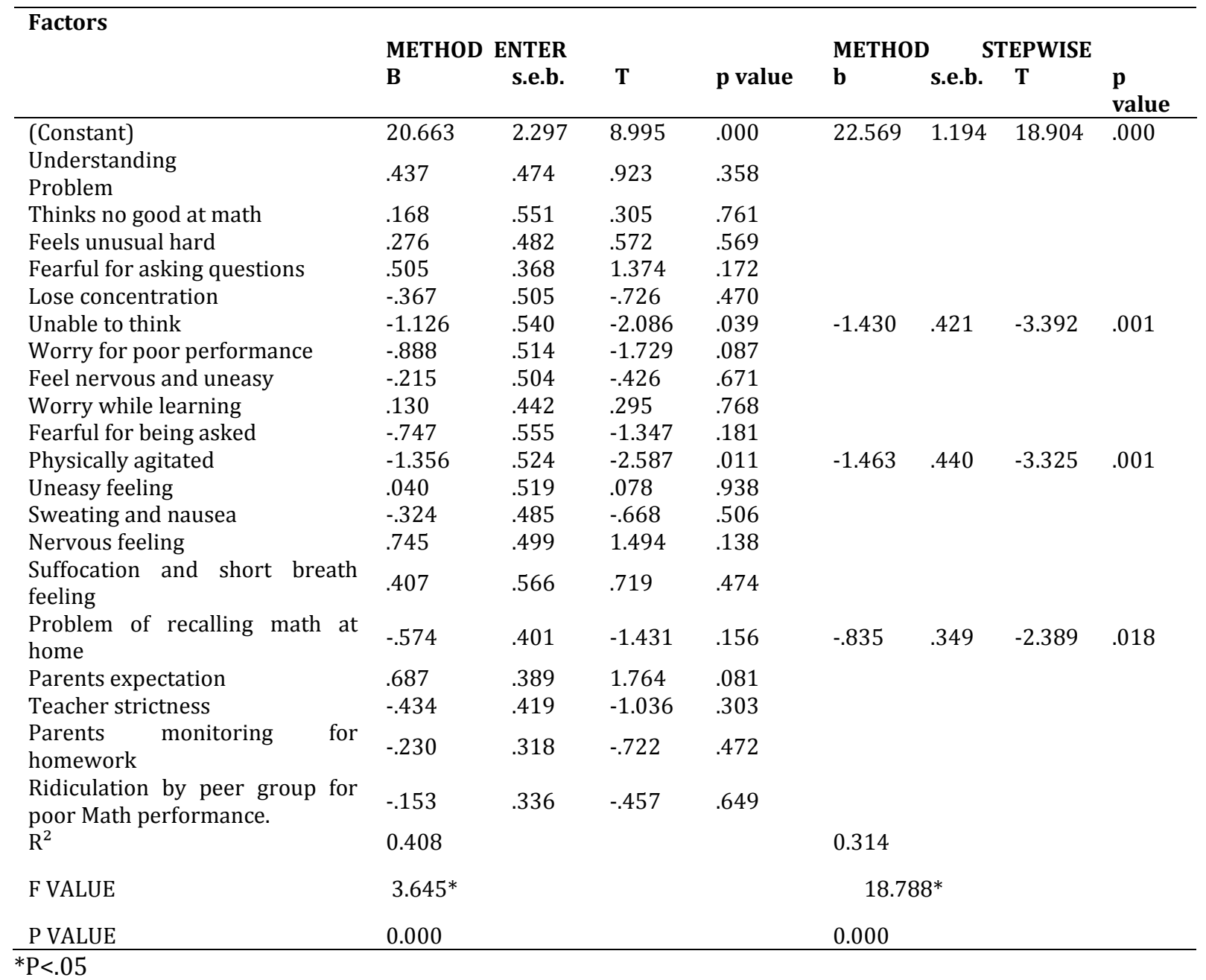

By using method enter of multiple regression analysis, it was found that the linear combination of the factors variables (Psychological and physical factors) was significant to influence "Total skills in Performance in Mathematics" at the level of significance $\alpha=0.05 \mathrm{~F}=3.645$, and $\mathrm{p}$ value $=0.00$. Among the 20 factors variables, only 2 factors, namely "Unable to think" and "Physically agitated" were significant to influence Overall skills in Performance in Mathematics at the level of significance $\alpha=0.05$ with $t$-values of2.086 and -2.587 with p-value of.039 and .011 respectively. It was also found that the coefficient of determination, $\mathrm{R}^{2}$ was $\mathbf{0 . 4 0 8}$, which means that $40.8 \%$ of the variation in the criterion variable, "Level of Performance in Mathematics" was accounted for, by the linear combination of the factors variables. By using the stepwise multiple regression analysis, it was found that among the Math Anxiety factors, "Unable to think, physically agitated and Problem of recalling Math at home" were the factors that influence the Performance in Mathematics of Grade 4 students in selected International schools in Bangkok.

\section{Discussion and Summary of Findings}

- Comprehension skills have the highest level of performance in Mathematics of the Grade 4 students in selected international schools in a Bangkok. Comprehension skills of the students are up to the expected level or highest level with mean of 3.24 or High among all the skills. Knowledge skills is lowest level with mean of 1.00 or very low. That means their grasping of meaning, making comparisons, summarization and grasping of meaning of Mathematics is very effective but their facts, principles, retention of terminology, and conventions are weak.

- Environmental Factor has the highest level of Mathematics Anxiety among all the factors with the mean of 15.57 or High. Physical factor has the moderate level of Mathematics Anxiety among all 
the factors with the mean is 10.42.This means that Mathematics anxiety could develop as a result of a student's prior negative experiences learning mathematics in the classroom or at home (Rossnan, 2006).

- The factors that most influenced in Performance in Mathematics is Physical factors. This is followed by Environmental factors and Psychological factors .The least influenced factors on Performance in Mathematics are Cognitive factors. Mathematics anxiety can impudence student's Performance in Mathematics physically by affecting memory (Kogelman and Warren, 1978) and creating nervousness and an inability to concentrate (Tobias, 1978). Cockcroft (1982) found people developing coping strategies for everyday life, and Brady and Bowd (2005) describe people avoiding Mathematics where possible.

\section{Conclusion}

Based on the foregoing findings, the following conclusions are drawn:

- It can be concluded that the findings of the study, the comprehension skills is the highest in the performance of the Grade 4 students in Mathematics. According to Bloom's taxonomy however the skills sequence should start with knowledge, followed by comprehension, application, analysis, synthesis and then evaluation .The findings of the study contradicts Bloom's sequence of skills.

- Environmental Factors produce the highest level of Mathematics Anxiety level among students. It shows that it is in the home and the classroom of the respondents displays very high Mathematics Anxiety.

- Physical factor has the highest influence in the Performance in Mathematics. This is followed by environmental factors, psychological factors with cognitive factors having the least influence.

"Physically agitated" is the most important factor from Physical factor which influence the Performance in Mathematics. The respondents get more nervous and ultimately affects on their Performance in Mathematics.

\section{Recommendations}

- Knowledge skills were the lowest level in the performance in the Mathematics. This requires $\mathrm{s}$ recalling memorized information. It is recommended therefore that knowledge skills be developed among the students intensively. This involves remembering a wide range of material from specific facts to complete theories. All that is required is the bringing to mind of the appropriate information, to know common terms, know specific facts, know methods and procedures, know basic concepts, and know principles. The Knowledge Dimension is the "knowing what."

- Since environmental factor produces the highest level of anxiety, it is recommended, that there be Parental involvement in reducing anxiety .Parents' role should be recognized in changing attitudes toward mathematics. Parents need to take a proactive role in the education of their children (Furner \& Berman, 2003). Supportive parents contribute to the success of their children while unsupportive ones add to the academic problems (Silva, 3 Tadeo, Reyes, \& Dadigan, 2006). Parents should talk with their children about their anxieties. They should discuss the feelings that the child associates with mathematics and try to pin point when the children started to experience these feelings (Rossnan, 2006). Oxford and Vordick (2006) stated that there are many more influences that are believed to help cause mathematics anxiety. The teacher's attitude is a major factor since students do not want to teach a subject that the teacher seems uninterested in or uncomfortable with. Other issues include impractical applications, high volumes of assigned problems, and short time spans to complete an assignment. McNaught (2007) indicated that good teachers are able to create a learning environment in which students have high and positive expectations about their learning, co-operative behavior is pronounced, and the culture encourages learning to occur. Rossnan (2006) suggested that teachers and parents should work together to assure every students that learning mathematics is important, relevant, and fun so that they can learn the mathematics skills that they need to succeed.

- Peer engagement makes a direct contribution to student's learning and success. Peer may provide instrumental aid, by teaching or tutoring their friends, by helping them keep track of assignments or by studying together. These supports would make students efforts more effective, in terms of both learning and graded performances on homework, projects, and tests 
(Kindermann\& Skinner, 2008). Shields (2006) reported that society plays a large role in the development of mathematics anxiety. For some reason, mathematics seems to be the only subject which people can express their lack of knowledge and hate for, and still be considered socially acceptable, normal contributors to society.

- Physical factor should be attended to because it has the highest influence in Mathematics Performance. Students can learn relaxation anxiety management techniques that are very effective in controlling the emotional and physical characteristics of anxiety that are interfering with mental processing capabilities. Teachers should be aware of the main factors which causes the mental and ultimately physical disability of the students which harms their Performance in Mathematics

\section{References}

Alexander, L. \& Martray, C. (1989). The development of an abbreviated version of the Mathematics Anxiety Rating Scale. Measurement and Evaluation in Counseling and Development, 22, 143-150.

Ashcraft, M. H. \& Faust, M. W. (1994). Mathematics anxiety and mental arithmetic performance: An exploratory investigation. Cognition and Emotion, 8, 97-125.

Ashcraft, M. H. \& Kirk, E. P. (2001). The relationships among working memory, math anxiety, and performance. Journal of Experimental Psychology - General, 130(2), 224-237.

Brady, P. \& Bowd, A. (2005). Mathematics anxiety, prior experience and confidence to teach mathematics among pre-service education students. Teachers and Teaching: Theory and Practice, 11(1), 37-46.

Cockcroft, W. H. (1982). Mathematics counts: report of the commission of inquiry in to the teaching of mathematic in school, Her Majesty's office, London

Fennema, E. (1977). Influence of selected cognitive, affective and educational variableson sex related differences in Mathematics learning and studying(National Institute of education papersin Education and work ,No.8,US.Department of Health, Education and Welfare)

Fennema, E. \& Sherman, J. A. (1976). Fennema-Sherman Mathematics Attitudes Scales: Instruments designed to measure attitudes toward the learning of mathematics by males and females. Catalog of Selected Documents in Psychology, 6(1), 31.

Fox, L. H. (1977). The effects of sex role socialization on mathematics participation and achievement (National Institute of education papers in Education and work, No.8, U.S, department of Health, Education and welfare)

Furner, J. M. \& Berman, B. T. (2003). Confidence in their ability to mathematics: The need to eradicate math anxiety so our future students can successfully compete in a high-tech globally, competitive world Florida Atlantic University and Contra Costa County Office of Education

Hembree, R. (1990). The nature, effects and relief of mathematics anxiety. Journal for Research in Mathematics Education, 21(1)33-46.

Institute for the Promotion of Teaching Science and Technology. (1997). Report Research and Evaluation with the Third International Mathematics and Science Study. Education journal in 12 years, 2, 6475.

Jackson, C. D. \&Leffingwell, R. J. (1999).The role of instructors in creating math anxiety in students from kindergarten through college. Mathematics teacher, 92(7), 583.

Kindermann, T. A. \& Skinner, E. A. (2008). How do naturally existing peer groups shape children's academic development during sixth grade? European Journal of Developmental Science, 2(14).

Kogelman, S. \& Warren, J. (1978). Mind over Math. New York: McGraw Hill.

Lewis, L. (2001). Add it up; Using research to improve education for low income and minority students.

McNaught, K. (2007). The power of writing for all pre-service mathematics teachers. Mathematics: Essential Research. Essential Practice, 2, 473-481.

Mercer, C. D. \& Mercer, A. R. (1998). Teaching students with learning problems (5 ${ }^{\text {th }}$ ed.). Upper Saddle River, NJ: Prentice-Hall Inc

Mercer, C. D., Lane, H. B., Jordan, L, Allsopp, D. H. \& Eisele, M. R. (1996). Empowering teachers and students with instructional choices in inclusive settings. Remedial and Special Education, 17, 226236.

Mercer, C. D., Jordan, L. \& Miller, S. P. (1996). Constructivistic math instruction for diverse learners. Learning Disabilities Research and Practice, 11, 147-156.

Miller, S. P. \& Mercer, C. D. (1997).Educational aspects of mathematics disabilities. Journal of Learning Disabilities, 30, 47-56.

Montagano, J. (2010). Educational and counseling Psychology Department, Andrew University, Barrien Springs, MI 49104-0104. 
Natcha, P. \& Satoshi, N. (2006). Analysis of Mathematics Performance of Grade Five Students in Thailand Using Newman Procedure "ICE Hiroshima University. Journal of International Cooperation in Education, 9(1), 111-122.

Oxford, J. \& Vordick, T. (2006). Math anxiety at Tarleton State University: An empirical report. Tarleton State University.

Plake, B. S. \& Parker, C. S. (1982). The development and validation of a revised version of the Mathematics Anxiety Rating scale. Educational and Psychological measurement, 42(2),551-557

Richardson, F. C. \& Suinn, R. M. (1972).The Mathematics Anxiety Rating Scale. Journal of Counseling Psychology, 19, 551-554.

Richardson, F. C. \& Woolfolk, R. L. (1980).Mathematics anxiety. In I. G. Sarason (Ed.), Test anxiety: Theory, research and application (pp. 271-288). Hillsdale, NJ: Erlbaum.

Rossnan, S. (2006).Overcoming math anxiety. Mathitudes, 1(1), 1-4.

Rounds, J. \& Hendel, D. (1980). Measurement and dimensionality of mathematics anxiety. Journal of Counseling Psychology, 27, 138-149.

Sakorn, P., Tayruakham, S. \& Nuangchalerm. P. (2009). Factors Influencing Mathematic Problem-Solving Ability of Sixth Grade Students. Journal of Social Sciences, 10, 381-385

Shields, D. J. (2006). Causes of math anxiety: The student perspective. Unpublished doctoral dissertation, Indiana University of Pennsylvania, Indiana.

Silva, D. L., Tadeo, M. C., Reyes, C. R. \& Dadigan, R. M. (2006). Factors associated with non-performing Filipino students in Mathematics: A vision of student's cognitive and behavior management. In the Proceedings of the 2nd IMT-GT Regional Conference of Mathematics, Statistics and Applications, University Sains Malaysia, Penang, June 13-15, 2006 (pp. 2-3).

Suinn, R. M., Edie, C. A., Nicoletti, J. \& Spinelli, P. R. (1972). The MARS, a measure of mathematics anxiety: Psychometric data. Journal of Clinical Psychology, 28, 373-375

Suinn, R. M. \& Winston, E .H. (2003). The Mathematic Anxiety Rating Scale, brief version, Psychometric data. Psychological reports, 92, 167-173.

Tobias, S. (1978). Overcoming Math Anxiety. Boston: Houghton Mifflin.

Tobias, S. \& Weissbrod, C. (1980). Anxiety and mathematics: An update. Harvard Educational Review, 50, 63-70.

UNESCO. (1990). Meeting Basic Learning Needs. Retrieved March, 2004 from http://www.unesco.org/education/efa/ed_for_all/background/jomtien_declaration.shtmahttp:/ /www.mentoringminds.com/research/critical-thinking-educator-wheel

Waanders, C., Mendez, J. L. \& Downer, J. T. (2007). Parent characteristics, economic stress and neighborhood context as predictors of parent involvement in preschool children's education. Journal of School Psychology, 45(6), 619-636.

WHO (1999-2000). Thailand Health Profile-Ministry of Public Health. Retrieved March, 2004 from 2004fromhttp://w3.whosea.org/eip/thf/English/tex\%20english_pdf/CHA4_2.pdf 